\title{
Descending endograft for DeBakey type 1 aortic dissection: pro
}

\author{
Paolo Berretta, Marco Di Eusanio \\ Division of Cardiac Surgery, G. Mazzini Hospital, Teramo, Italy \\ Correspondence to: Marco Di Eusanio. Cardiac Surgery Department, G. Mazzini Hospital, Piazza Italia, 64100 Teramo, Italy. \\ Email: marco.dieusanio@aslteramo.it.
}

\begin{abstract}
The surgical management of patients with DeBakey type 1 acute aortic dissection (DBT1-AAD) represents a major challenge for aortic surgeons. It has been demonstrated that the distal false lumen remains patent in about $70 \%$ to $80 \%$ of patients undergoing DBT1-AAD surgery and that a patent false lumen worsens the prognosis. In order to improve long term outcomes and reduce the frequency of late aneurysm formation and reoperation, a more aggressive primary operation involving total arch replacement (TAR) and concomitant antegrade stenting of the descending thoracic aorta (DTA) with a frozen elephant trunk (FET) has been introduced. Such extensive operations, however, remain controversial due to their increased technical complexity and perceived higher operative mortality and morbidity. This perspective article will overview the rationale behind, and the potential advantages and current evidence for, FET surgery in acute aortic dissection.
\end{abstract}

Keywords: Great vessels; aorta; acute dissection; hybrid repair

Submitted Jan 15, 2016. Accepted for publication Jan 28, 2016.

doi: $10.21037 /$ acs.2016.03.12

View this article at: http://dx.doi.org/10.21037/acs.2016.03.12

Despite improvements in diagnostic techniques and refinements in management strategies, DeBakey type 1 acute aortic dissection (DBT1-AAD) continues to represent a great challenge for aortic surgeons. The optimal surgical management is still an open question and several issues remain under debate. Emergency surgery is the mainstay of therapy but hospital mortality still ranges from $15 \%$ to $30 \%$ (1-4). Given the high risk profile of patients with acute aortic dissection and the technical complexity of the necessary interventions, a conservative tear-oriented aortic replacement (more often a supra-coronary ascending/ hemiarch replacement) with commissural resuspension and re-establishment of the dominant blood flow in the distal true lumen currently represents the most common surgical approach. However, it has been demonstrated that the distal false lumen remains patent in about $70 \%$ to $80 \%$ of patients undergoing surgery for DBT1-AAD dissection (5-8), and a wide and patent false lumen worsens the prognosis $(6,9-16)$ by increasing the risk of late death, re-intervention and aneurysmal dilatation of the remaining dissected aorta $(6,17-21)$. The regions with the highest risk of developing an aneurysm are the distal arch and proximal descending thoracic aorta (DTA) (17,22-24). In patients undergoing
DBT1-AAD repair, freedom from aortic reoperation at 10 years ranges from $61 \%$ to $74 \%(10,20,25)$. To reduce the frequency of late aneurysm formation and reoperation, some surgeons have been motivated to perform more aggressive primary operations, all associated with strengths and weaknesses. Recently, total arch replacement (TAR) and concomitant antegrade stenting of the DTA with a frozen elephant trunk (FET) has emerged as an interesting form of treatment for patients with extensive DBT1-AAD, and its application has significantly increased over recent years (26). Different methods of how to perform this procedure have been described, but the common feature is that, under hypothermic circulatory arrest, the stent graft is delivered antegradely into the DTA through the open aorta and sutured into position while the transverse arch is replaced with a Dacron graft. Such extensive operations, however, remain controversial due to their increased technical complexity and perceived higher operative mortality and morbidity.

\section{Arguments for DTA endograft during DeBakey type 1 acute aortic dissection repair (DBT1-AAD)}

As opposed to more conservative interventions, the 
rationales for TAR and concomitant antegrade stenting of the DTA, lies in its potential to more effectively treat patients with complex primary and re-entry intimal tears in the distal aortic arch and/or proximal DTA, optimize true lumen perfusion and minimize the effects of distal malperfusion and promote distal thoracic aortic remodelling and reduce late aortic events associated with a patent false lumen.

\section{Distal arch tears and extensive arch disease}

Complete resection of the primary intimal tear is mandatory for obtaining satisfactory early and long-term results in patients with acute aortic dissection (27-29). In patients with severe aortic arch compromise by the dissecting process, TAR seems to be more effective than a conservative approach in avoiding bleeding, anastomotic leak, progression of aneurysmal dilatation, aortic rupture, reoperation and brain injury $(11,27,28)$. In this setting, the FET technique is a valuable adjunct to TAR in patients with complex primary and re-entry tears involving the distal arch and proximal DTA, distal arch and DTA rupture, an aneurysmal arch and proximal DTA, and a severely damaged aortic arch hampering safe distal aortic arch anastomosis. The FET construction may facilitate surgery by avoiding complex and unsafe distal anastomoses, performed at the level of the proximal DTA at high risk of rupture or bleeding due to the fragile dissected aortic wall. In fact, by taking advantage of the distal stent-graft with the FET technique, a distal anastomosis can be more easily carried out at a more proximal level (proximal to the left subclavian or left common carotid artery), still achieving valid exclusion of the distal arch tear (30). Furthermore, by avoiding persistent DTA false lumen perfusion, FET enhances haemostasis at the distal anastomotic site.

\section{Distal malperfusion}

It has been estimated that distal malperfusion syndromes occur in up to $30 \%$ of patients, and represent one of the strongest determinants of early death in TAAD patients (31-33). Stent-grafting the DTA may offer the potential to more rapidly reverse the malperfusion process by opening the compressed true lumen and covering additional entry tears located in the proximal DTA, which endure pressurization of the false lumen.

Recently, several groups reported encouraging results using this approach, and showed how FET techniques (which are often associated with secondary endovascular procedures to optimize final results) can result in superior outcomes for this high-risk group of malperfused patients when appropriately employed in hybrid operative rooms by a multidisciplinary team $(34,35)$.

\section{Distal aortic remodelling}

In TAAD patients, limited aortic resections have been associated with poor distal aortic remodelling due to distal false lumen degeneration. Late distal aortic complications, including aneurysmal degeneration, rupture, malperfusion and the need for extensive re-interventions have been observed in up to $70 \%$ of patients undergoing TAAD repair $(18,36)$. In acute dissection, antegrade stenting of DTA at initial surgery, by inducing both coverage of the secondary entry tears located in the proximal DTA and obliteration of the false lumen at the proximal DTA, is expected to mitigate DTA dilatation and, therefore improve long-term survival by reducing aortic-related deaths and the need for complex distal aortic re-interventions.

Progression of the aortic disease seems to be related to some anatomical variables that, in the acute or sub-acute phase, may portend poor long-term outcomes and that might support, in appropriate conditions, a prophylactic stenting of DTA. In particular, a DTA diameter at initial presentation $>35 \mathrm{~mm}$ was found to be a risk factor for a patent false lumen postoperatively (24); an initial false lumen diameter $\geq 22 \mathrm{~mm}$ was associated with accelerated aortic dilatation and occurrence of adverse aortic events (37), and a large proximal intimal tear $(>10 \mathrm{~mm})$ emerged as risk factor for dissection related events and mortality (38). Moreover, Marfan syndrome or other connective tissue diseases are well-known risk factors for distal aortic reintervention $(3,38)$. The use of stent-grafts in Marfan patients is controversial mostly due to the young age of these patients, the limited long-term data available for the endovascular procedures and the increased risk of stentrelated degeneration of the weakened Marfan aortic wall. The latter can lead to stent-graft migration and occurrence of proximal and distal endoleaks. However, using FET technique, stent migration and proximal endoleak seem to be prevented due to the suture of the stent graft to the proximal descending aorta (39).

TAR using FET technique in DBT1-AAD patients is a highly demanding and time consuming operation which mandates thorough experience with the surgical and endovascular forms of the therapy for aortic dissection and 
optimal methods of organ protection. Therefore not all patients, and not all surgeons, are good candidates for the FET technique and this procedure should be performed by experienced aortic surgeons in patients who are deemed to have physical conditions sufficient to withstand such major interventions (26).

\section{Current evidence}

Recently, a systematic review and meta-analysis was performed to assess results of antegrade stenting of DTA during TAAD surgery (26). In-hospital mortality (10\%) and stroke $(4.8 \%)$ rates were extremely satisfactory while the risk of spinal cord injury (4.3\%) appeared to be higher than that reported in more conservatively managed series. In this setting, lately, Katayama et al. showed that in patients undergoing FET, postoperative spinal cord injury may be prevented or minimized by avoiding deep insertion of the stent graft, keeping blood pressure elevated after the operation and using cerebrospinal fluid drainage (40). Nevertheless, the spinal cord injury remains the main Achilles heel of FET procedure.

To date, there has been limited long-term data published on aortic remodelling, re-interventions and survival after DTA stent-grafting in TAAD patients. One-year survival ranged from $79 \%$ to $100 \%$, 5-year survival ranged from $68 \%$ to $96 \%$ and 1 -year freedom from re-intervention from $72 \%$ to $100 \%(41-47)$. In the above mentioned metaanalysis, the pooled average of aortic remodelling, indicated by a partial or complete thrombosis of the persistent DTA false lumen, was $88.9 \%$ (26). Despite this imaging data comparing favourably with the imaging data reported for conservative management $(20,48)$, a substantial survival benefit of the FET techniques has yet to be demonstrated, and more robust data is necessary to standardize new paradigms of treatment in patients with acute dissection.

\section{Conclusions}

Current evidence suggests the DTA endograft plays an increasingly important role in modern DBT1-AAD surgery. Patients with complex arch tears involving the distal arch and/or proximal DTA, and patients with distal malperfusion and compression of the true lumen at the DTA certainly represent an interesting subset for FET application. When used by experienced surgeons on selected patients, these techniques have been associated with satisfactory early outcomes, encouraging long-term radiological results and fewer re-intervention rates. Nevertheless, stronger evidence is still needed to assess long term clinical outcomes in this setting.

\section{Acknowledgements}

None.

\section{Footnote}

Conflicts of Interest: The authors have no conflicts of interest to declare.

\section{References}

1. Trimarchi S, Nienaber CA, Rampoldi V, et al. Contemporary results of surgery in acute type A aortic dissection: The International Registry of Acute Aortic Dissection experience. J Thorac Cardiovasc Surg 2005;129:112-22.

2. Conzelmann LO, Weigang E, Mehlhorn U, et al. Mortality in patients with acute aortic dissection type A: analysis of pre- and intraoperative risk factors from the German Registry for Acute Aortic Dissection Type A (GERAADA). Eur J Cardiothorac Surg 2016;49:e44-52.

3. Geirsson A, Bavaria JE, Swarr D, et al. Fate of the residual distal and proximal aorta after acute type a dissection repair using a contemporary surgical reconstruction algorithm. Ann Thorac Surg 2007;84:1955-64; discussion 1955-64.

4. Knipp BS, Deeb GM, Prager RL, et al. A contemporary analysis of outcomes for operative repair of type A aortic dissection in the United States. Surgery 2007;142:524-8; discussion 528.e1.

5. Moore NR, Parry AJ, Trottman-Dickenson B, et al. Fate of the native aorta after repair of acute type A dissection: a magnetic resonance imaging study. Heart 1996;75:62-6.

6. Park KH, Lim C, Choi JH, et al. Midterm change of descending aortic false lumen after repair of acute type I dissection. Ann Thorac Surg 2009;87:103-8.

7. Turley K, Ullyot DJ, Godwin JD, et al. Repair of dissection of the thoracic aorta. Evaluation of false lumen utilizing computed tomography. J Thorac Cardiovasc Surg 1981;81:61-8.

8. Yamaguchi T, Guthaner DF, Wexler L. Natural history of the false channel of type A aortic dissection after surgical repair: CT study. Radiology 1989;170:743-7.

9. Fann JI, Smith JA, Miller DC, et al. Surgical management 
of aortic dissection during a 30-year period. Circulation 1995;92:II113-21.

10. Kirsch M, Soustelle C, Houël R, et al. Risk factor analysis for proximal and distal reoperations after surgery for acute type A aortic dissection. J Thorac Cardiovasc Surg 2002;123:318-25.

11. Bachet J, Goudot B, Dreyfus GD, et al. Surgery for acute type A aortic dissection: the Hopital Foch experience (1977-1998). Ann Thorac Surg 1999;67:2006-9; discussion 2014-9.

12. Crawford ES, Kirklin JW, Naftel DC, et al. Surgery for acute dissection of ascending aorta. Should the arch be included? J Thorac Cardiovasc Surg 1992;104:46-59.

13. Heinemann M, Laas J, Karck M, et al. Thoracic aortic aneurysms after acute type A aortic dissection: necessity for follow-up. Ann Thorac Surg 1990;49:580-4.

14. Gariboldi V, Grisoli D, Kerbaul F, et al. Long-term outcomes after repaired acute type A aortic dissections. Interact Cardiovasc Thorac Surg 2007;6:47-51.

15. Kimura N, Tanaka M, Kawahito K, et al. Early postoperative aortic rupture following surgery for acute type A aortic dissection. Interact Cardiovasc Thorac Surg 2009;8:431-4.

16. Bachet JE, Termignon JL, Dreyfus G, et al. Aortic dissection. Prevalence, cause, and results of late reoperations. J Thorac Cardiovasc Surg 1994;108:199-205; discussion 205-6.

17. Akutsu K, Nejima J, Kiuchi K, et al. Effects of the patent false lumen on the long-term outcome of type B acute aortic dissection. Eur J Cardiothorac Surg 2004;26:359-66.

18. Halstead JC, Meier M, Etz C, et al. The fate of the distal aorta after repair of acute type A aortic dissection. J Thorac Cardiovasc Surg 2007;133:127-35.

19. Yeh $\mathrm{CH}, \mathrm{Chen} \mathrm{MC}, \mathrm{Wu} \mathrm{YC}$, et al. Risk factors for descending aortic aneurysm formation in medium-term follow-up of patients with type A aortic dissection. Chest 2003;124:989-95.

20. Zierer A, Voeller RK, Hill KE, et al. Aortic enlargement and late reoperation after repair of acute type A aortic dissection. Ann Thorac Surg 2007;84:479-86; discussion 486-7.

21. Bachet J, Teodori G, Goudot B, et al. Replacement of the transverse aortic arch during emergency operations for type A acute aortic dissection. Report of 26 cases. J Thorac Cardiovasc Surg 1988;96:878-86.

22. Kimura N, Tanaka M, Kawahito K, et al. Influence of patent false lumen on long-term outcome after surgery for acute type A aortic dissection. J Thorac Cardiovasc Surg
2008;136:1160-6, 1166.e1-3.

23. Bernard Y, Zimmermann H, Chocron S, et al. False lumen patency as a predictor of late outcome in aortic dissection. Am J Cardiol 2001;87:1378-82.

24. Sakaguchi G, Komiya T, Tamura N, et al. Patency of distal false lumen in acute dissection: extent of resection and prognosis. Interact Cardiovasc Thorac Surg 2007;6:204-7.

25. Tan ME, Morshuis WJ, Dossche KM, et al. Long-term results after 27 years of surgical treatment of acute type a aortic dissection. Ann Thorac Surg 2005;80:523-9.

26. Di Eusanio M, Castrovinci S, Tian DH, et al. Antegrade stenting of the descending thoracic aorta during DeBakey type 1 acute aortic dissection repair. Eur J Cardiothorac Surg 2014;45:967-75.

27. Kazui T, Washiyama N, Bashar AH, et al. Surgical outcome of acute type A aortic dissection: analysis of risk factors. Ann Thorac Surg 2002;74:75-81; discussion 81-2.

28. Moon MR, Sundt TM 3rd, Pasque MK, et al. Does the extent of proximal or distal resection influence outcome for type A dissections? Ann Thorac Surg 2001;71:1244-9; discussion 1249-50.

29. Heinemann M, Laas J, Jurmann M, et al. Surgery extended into the aortic arch in acute type A dissection. Indications, techniques, and results. Circulation 1991;84:III25-30.

30. Di Eusanio M, Petridis FD, Pacini D, et al. Facilitated aortic arch repair with the frozen elephant trunk technique. Eur J Cardiothorac Surg 2011;40:1261-2.

31. Geirsson A, Szeto WY, Pochettino A, et al. Significance of malperfusion syndromes prior to contemporary surgical repair for acute type A dissection: outcomes and need for additional revascularizations. Eur J Cardiothorac Surg 2007;32:255-62.

32. Girdauskas E, Kuntze T, Borger MA, et al. Surgical risk of preoperative malperfusion in acute type A aortic dissection. J Thorac Cardiovasc Surg 2009;138:1363-9.

33. Di Eusanio M, Trimarchi S, Patel HJ, et al. Clinical presentation, management, and short-term outcome of patients with type A acute dissection complicated by mesenteric malperfusion: observations from the International Registry of Acute Aortic Dissection. J Thorac Cardiovasc Surg 2013;145:385-390.e1.

34. Roselli EE, Rafael A, Soltesz EG, et al. Simplified frozen elephant trunk repair for acute DeBakey type I dissection. J Thorac Cardiovasc Surg 2013;145:S197-201.

35. Tsagakis K, Konorza T, Dohle DS, et al. Hybrid operating room concept for combined diagnostics, intervention and surgery in acute type A dissection. Eur J Cardiothorac Surg 2013;43:397-404. 
36. Fattouch K, Sampognaro R, Navarra E, et al. Longterm results after repair of type a acute aortic dissection according to false lumen patency. Ann Thorac Surg 2009;88:1244-50.

37. Song JM, Kim SD, Kim JH, et al. Long-term predictors of descending aorta aneurysmal change in patients with aortic dissection. J Am Coll Cardiol 2007;50:799-804.

38. Evangelista A, Salas A, Ribera A, et al. Long-term outcome of aortic dissection with patent false lumen: predictive role of entry tear size and location. Circulation 2012;125:3133-41.

39. Ius F, Fleissner F, Pichlmaier M, et al. Total aortic arch replacement with the frozen elephant trunk technique: 10-year follow-up single-centre experience. Eur J Cardiothorac Surg 2013;44:949-57.

40. Katayama K, Uchida N, Katayama A, et al. Multiple factors predict the risk of spinal cord injury after the frozen elephant trunk technique for extended thoracic aortic disease. Eur J Cardiothorac Surg 2015;47:616-20.

41. Weiss G, Santer D, Dumfarth J, et al. Evaluation of the downstream aorta after frozen elephant trunk repair for aortic dissections in terms of diameter and false lumen status†. Eur J Cardiothorac Surg 2016;49:118-24.

42. Shi E, Gu T, Yu L, et al. Repair of Stanford type A aortic dissection with ascending aorta and hemiarch replacement

Cite this article as: Berretta P, Di Eusanio M. Descending endograft for DeBakey type 1 aortic dissection: pro. Ann Cardiothorac Surg 2016;5(3):222-226. doi: 10.21037/ acs.2016.03.12 combined with stent-graft elephant trunk technique by using innominate cannulation. J Thorac Cardiovasc Surg 2011;142:1458-63.

43. Chen X, Huang F, Xu M, et al. The stented elephant trunk procedure combined total arch replacement for Debakey I aortic dissection: operative result and follow-up. Interact Cardiovasc Thorac Surg 2010;11:594-8.

44. Pochettino A, Brinkman WT, Moeller P, et al. Antegrade thoracic stent grafting during repair of acute DeBakey I dissection prevents development of thoracoabdominal aortic aneurysms. Ann Thorac Surg 2009;88:482-9; discussion 489-90.

45. Jakob H, Tsagakis K, Pacini D, et al. The International E-vita Open Registry: data sets of 274 patients. J Cardiovasc Surg (Torino) 2011;52:717-23.

46. Hoffman A, Damberg AL, Schälte G, et al. Thoracic stent graft sizing for frozen elephant trunk repair in acute type A dissection. J Thorac Cardiovasc Surg 2013;145:964-9.

47. Sun L, Qi R, Zhu J, et al. Repair of acute type A dissection: our experiences and results. Ann Thorac Surg 2011;91:1147-52.

48. Watanuki H, Ogino H, Minatoya K, et al. Is emergency total arch replacement with a modified elephant trunk technique justified for acute type A aortic dissection? Ann Thorac Surg 2007;84:1585-91. 